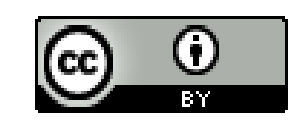

Esta obra está sob o direito de Licença Creative Commons Atribuição 4.0 Internacional.

\title{
O BRINCAR COMO INSTRUMENTO DA ENGRENAGEM NO DESENVOLVIMENTO NEUROPSICOMOTOR INFANTIL
}

\author{
Silvania Moura da Silva ${ }^{6}$ \\ Euclides Maurício Trindade Filho ${ }^{7}$ \\ Izabelle wanessa campos galindo 8 \\ Antônio Alberto monteiro de souza ${ }^{9}$ \\ David jefferson da silva ${ }^{10}$ \\ Betijane Soares de Barros ${ }^{11}$
}

\begin{abstract}
RESUMO
O brincar e brincadeiras inseridas na educação infantil têm um papel importante para aprimoramento integral das crianças. O objetivo da pesquisa foi verificar a influência do brincar na aquisição dos componentes de desempenho em alunos de 03 anos de ambos os sexos em seu espaço escolar. Foram selecionadas 20 participantes na primeira avaliação e para reavaliação participaram apenas 14. A descrição dos resultados foi feita utilizando uma análise quantitativa, intervencionista e longitudinal prospectivo. O local da pesquisa, no Centro Municipal de Educação Infantil - CMEI da Rede de Ensino da Cidade de Maceió, Alagoas. Para a coleta de dados foram utilizados à escala DENVER II, como uma ferramenta que norteou os possíveis riscos de atraso no desenvolvimento. Os resultados da pesquisa mostraram que as crianças que mais apresentaram atraso no desenvolvimento neuropsicomotor foi o grupo de 3 anos a 3,2 meses com $45 \%$ de presença nos quesitos em ambos os casos, motor fino adaptativo e motor grosso. Após orientações nas tarefas semi-estruturadas, ocorreu um aumento significativo nas habilidades da coordenação motora fina de $54 \%$ e coordenação motora grossa de $60 \%$.
\end{abstract}

Palavras-chave: Brincar, Desenvolvimento infantil, Aprendizagem.

\footnotetext{
${ }^{6}$ Terapeuta Ocupacional/UNCISAL, melsil12@hotmail.com

7 emtfilho@gmail.com, PhD em neurociência, Professor adjunto de Fisiologia Humana por imagem da

Universidade Estadual de Ciências da Saúde de Alagoas - UNCISAL.

${ }^{8}$ Terapeuta Ocupacional izabelle_wanessa@homail.com

${ }^{9}$ EngenheiroCivil/UFAL, aamonteirodesouza@gmail.com

10 graduado em advocacia/Mauricio de Nassau, davi26.bsm@ hotmail.com

11 bj-sb@hotmail.com
} 


\section{INTRODUÇÃO}

A infância é considerada uma fase importante do desenvolvimento, onde otimizam diversas aptidões que favorecem na evolução de aquisições de suas habilidades motoras e cognitivas. De acordo com Campos (2017), a vivência que acontece habitualmente e que esteja relacionada com o meio externo, tendem proporcionar experiências que irão conduzir ao amadurecimento durante a fase do desenvolvimento.

Fundamenta-se no pressuposto de Burckardt et. al. (2018) que o brincar é uma ferramenta que possibilita a criança usar a criatividade, produzir fantasia e se relacionar com a realidade, onde suas ações norteadas pelas brincadeiras tendem construir uma ligação consigo e com outras pessoas.

A brincadeira é uma tarefa que ocupa a maior parte do dia a dia da criança e é considerada essencial para o desenvolvimento infantil, e diante dessa percepção, a engrenagem do brincar e do brinquedo possibilita-a criar, recriar, fazendo que viva o momento com o significativo (BURCKARDT et.al. 2018). E ainda, a ação do brincar é um afazer que aperfeiçoa as capacidades "cognitivas, emocionais, psicomotoras e sociais". Suas experiências adquiridas no meio que estão inseridas permitem compartilhar a aprendizagem e a interagir umas com as outras (CAMPOS et. al. 2017).

Adreeta, et al (2020), enfatizam que na escola é um espaço rico para aprender, aprimorar as habilidades do aluno, e que nele a ludicidade seja inserida em diversos contextos, pois por meio do lúdico se permite adquirir êxito em seu aprendizado.

$\mathrm{Na}$ acepção de Porta et al (2016) aprendizagem se dá por meio de mecanismo provenientes do ambiente em que a criança possa relacionar-se com os que estão a sua volta e consequentemente aprimorando suas aptidões. Deste modo, um local adequado para sua aprendizagem irá favorecer na interação cerebral mediante a estimulação do ambiente. Ressalta ainda, que o cérebro recebe estímulos a partir de influências do cotidiano que engloba contextos históricos e costumes do meio que estão inseridos, essas interações, por sua vez, são uma engrenagem do desenvolvimento neuropsicomotor infantil.

Foi observado também no estudo de Tolocka, et al (2016), a importância do espaço lúdico para auxiliar no processo da aprendizagem da criança e que os professores como promovedores do saber, são uma âncora para conduzir as brincadeiras. Explica ainda, que a criança ao brincar com outras de idade diferente em seu contexto escolar, podem aprimorar suas habilidades psicomotoras e a interagir socialmente.

Para Melo et al (2017) a aprendizagem se dá por meio da neuroplasticidade cerebral, que é a capacidade de mudar, adapta-se e molda-se de acordo com o ambiente que a criança está inserida.

Em vista disso, o brincar na escola é uma ferramenta que pode possibilitar a criança desenvolver suas habilidades motoras, uma vez que exercita o corpo em diferentes modalidades, favorece no processo da aquisição do conhecimento, elaboração de conceitos, criatividade e a imaginação (FREITAS; CORSO, 2016).

Este estudo verificou a influência do brincar para crianças na aquisição dos componentes de desempenho ocupacional em seu contexto escolar e os dados sociodemográficos dos familiares. 


\section{METODOLOGIA}

Estudo

quantitativo, intervencionista e longitudinal prospectivo, realizado com crianças de 3 anos a 3 anos e 11 meses de uma Creche da rede do Centro Municipal de Educação Infantil - CMEI da Cidade de Maceió, Alagoas. A escolha da instituição ocorreu de uma forma intencional e deliberada, por trata-se de uma escola com profissionais qualificados e com a presença de espaço lúdico.

Amostra da unidade de ensino foi registrada 45 crianças matriculadas no ano de 2017, onde foram coletados apenas os dados de 20, sendo $45 \%$ meninos (9) e $55 \%$ meninas (11). Vinculado a uma Rede de ensino na cidade de Maceió/AL no ano de 2017 a 2018. Foram excluídos: 01 (uma) criança com alteração neurológica, $10 \mathrm{com}$ quatro faltas consecutivas, 06 desistências do ano letivo, 02 se negaram a participar da avaliação Denver II e 06 haviam completados os quatro anos de idade. Após exclusões da amostra por absentismo e transferência, participaram efetivamente até o final do estudo 14 escolares pertencentes ao maternal II, sendo 06 meninos (43\%) e 08 meninas (57\%). Nestes foi reaplicado a Escala Denver II para se obter informações do desempenho ocupacional.

O levantamento dos dados ocorreu entre os meses de agosto a dezembro de 2017 e janeiro a março de 2018. Transcorreu da seguinte maneira: agosto de 2017 ocorreu a aplicação do questionário semi-estruturado. Setembro a outubro, obedecendo as normas de funcionamento da escola, realizou-se a apreciação das crianças com a escala Denver II. Em novembro até primeira semana de dezembro de 2017 e fevereiro de 2018, foi executado atividades baseadas a partir da analises da avaliação.
O teste Denver II, o qual representa um teste de triagem e não um teste de diagnóstico, onde classifica o desempenho como normal ou risco de atraso no desenvolvimento.

A escala, aplicável conforme faixa etária da criança é composta de 125 itens, distribuídos na avaliação de quatro áreas distintas do desenvolvimento neuropsicomotor. $\mathrm{O}$ comportamento pessoal-social ("nomeia amigos", "veste com ajuda", "escova dentes); motricidade fina-adaptativa (manuseio de pequenos objetos, coordenação viso-manual, tais como: "constrói torre de oito cubos", "balança o polegar", "cópia círculos", “desenha pessoas com três partes", "cópia cruz", "pega linha mais comprida"), linguagem ("sabe dois adjetivos", "sabe três adjetivos", "conhece duas ações", "uso de dois objetos", "nomeia uma cor", "nomeia quatro cores", "conta um bloco", "conta cinco blocos", "fala inteligível", "entende duas preposições"). Motricidade ampla ("pulo largo", "pula com uma perna só").

Para não mudar a rotina da creche, $o$ teste foi realizado durante o expediente normal. Utilizou-se uma sala de cerca de $4 \mathrm{~m} 2$ contendo mesa ou carteira para a pesquisadora e mesa pedagógica com cadeira adequada para a criança. Todas as crianças foram avaliadas individualmente, a depender do tempo de aplicabilidade do instrumento que cada uma necessitava, ou seja, tempo médio era 20 minutos.

A terapeuta ocupacional, Izabelle Wanessa Campos Galindo, CREFITO $\mathrm{n}^{\circ} 16167$, que possui especialização no método, foi quem conduziu a aplicação do instrumento aos participantes da pesquisa, realizando registros com anotações durante a execução das atividades correspondente a escala com o auxílio da pesquisadora.

Para a coleta dos dados secundários foi utilizado um questionário específico 
construído para este estudo, constando de dados sociodemográficos dos familiares.

As variáveis analisadas foram: com relação às crianças, o seu desempenho nas habilidades cognitiva, física e social; com relação aos familiares, renda total familiar, escolaridade, profissão e se participam de programas sociais.

Os dados foram apresentados na forma de média. As variáveis qualitativas foram apresentadas sob a forma de tabelas de frequência. A avaliação da afetividade da atividade do brincar padronizada sobre o desenvolvimento motor, cognitivo e da interação social foi realizada no teste do Qui-quadrado. Foi considerado significante quando $\mathrm{o}$ valor do $\mathrm{p}$ for $\leq 0,05 \mathrm{e}$ armazenados em planilha do Microsoft Excel 2013. Buscou-se preservar o anonimato dos participantes, identificando os questionários por um número inteiro natural, iniciando-se pelo algarismo 1 (um), até completar a lista das crianças selecionadas da pesquisa no período determinado de coleta dos dados.

O estudo foi aprovado pelo Comitê de Ética da Universidade Estadual de
Ciências da Saúde de Alagoas (UNCISAL), sob o CAAE 68984317.8.0000.5011 em 24 de junho de 2017, mediante autorização institucional e assinatura dos responsáveis legais do Termo de Consentimento Livre e Esclarecido (TCLE) e o Termo de Assentimento Livre e Esclarecido das crianças participantes da pesquisa, conforme a Resolução 466/2012 do Conselho Nacional de Saúde.

\section{RESULTADOS}

Os encontros ocorreram em dois períodos distintos: manhã e tarde, para avaliar as crianças com o Denver II, que foi criado por Frankenburg et al., em 1967, para detectar precocemente algumas condições do desenvolvimento infantil de o (zero) a 6 (seis) anos, avaliando quatro áreas: motor fino adaptativo, motor grosso, linguagem e pessoal-social (FRANKENBURG, et al.1992; MORAES, et al. 2010 e BREDAS, et al.1995). Analise das crianças, foram subdivididas em grupos de acordo com a idade, considerando de 03 anos a 03 anos e 11 meses (tabela 1).

Tabela 1.

Características das Crianças

Sexo

\begin{tabular}{c|c|c}
\hline Masculino & & $09(45 \%)$ \\
\hline Feminino & & $11(55 \%)$ \\
\hline Idade & & \\
\hline 3a - 3a e 2m & & $06(30 \%)$ \\
\hline 3a e 3m - 3a e 5m & & $04(20 \%)$ \\
\hline 3a e 6m - 3a e 8m & & $05(25 \%)$ \\
\hline 3a e 9m - 3a e 11m & $05(25 \%)$
\end{tabular}


Condições Sociodemográficos Dos Familiares

Foi aplicado questionário estruturado com o responsável das crianças, para se obter informações referentes a sua participação sócio-demográfica (Tabela 2). De acordo com a tabela, 50\% tem participação em programas sociais, $55 \%$ trabalha autônomo e é importante pontuar também que $50 \%$ dos responsáveis possuem o ensino fundamental incompleto. Esses pontos sociodemograficos, é sugestivo a pouca co-participação dos pais no desempenho escolar de suas crianças, onde $\mathrm{o}$ fator social determinam na formação do indivíduo, sendo assim, foi observado durante a pesquisa que as crianças apresentaram dificuldades em desenvolver as atividades propostas pelo instrumento durante avaliação Denver II, que possui os seguintes materiais que foram utilizados na avaliação: boneca de plástico, bola, 8 blocos coloridos e folha em branco e ainda figuras de um gato, cachorro, pássaro e menino.

\section{Tabela 2.}

\section{Caracterização Sociodemográfica dos familiares.}

\begin{tabular}{c|l|c}
\multicolumn{2}{c|}{ Renda Familiar } & \\
\hline Salário mínimo & & $04(20 \%)$ \\
\hline Sem renda fixa & & $06(30 \%)$ \\
\hline \multicolumn{2}{c|}{ Participação em programas sociais } & $10(50 \%)$ \\
\hline Profissão & & $11(55 \%)$ \\
\hline Autônomo & & $04(20 \%)$ \\
\hline Do lar & & $03(15 \%)$ \\
\hline Diarista & & $01(05 \%)$ \\
\hline Aposentada & & $01(05 \%)$ \\
\hline Segurança & & $10(50 \%)$ \\
\hline Escolaridade & & $02(10 \%)$ \\
\hline \multicolumn{2}{c|}{ Ensino fundamental incompleto } & $08(40 \%)$
\end{tabular}

No resultado da avaliação (tabela 3) foram verificados alguns dados qualitativos, tais como: maior número de falhas nos itens de motor fino adaptativo, motor grosso e na linguagem (tabela 3 ). 
Tabela 3

Resultado da Escala Denver II nas crianças de acordo com a faixa etária.

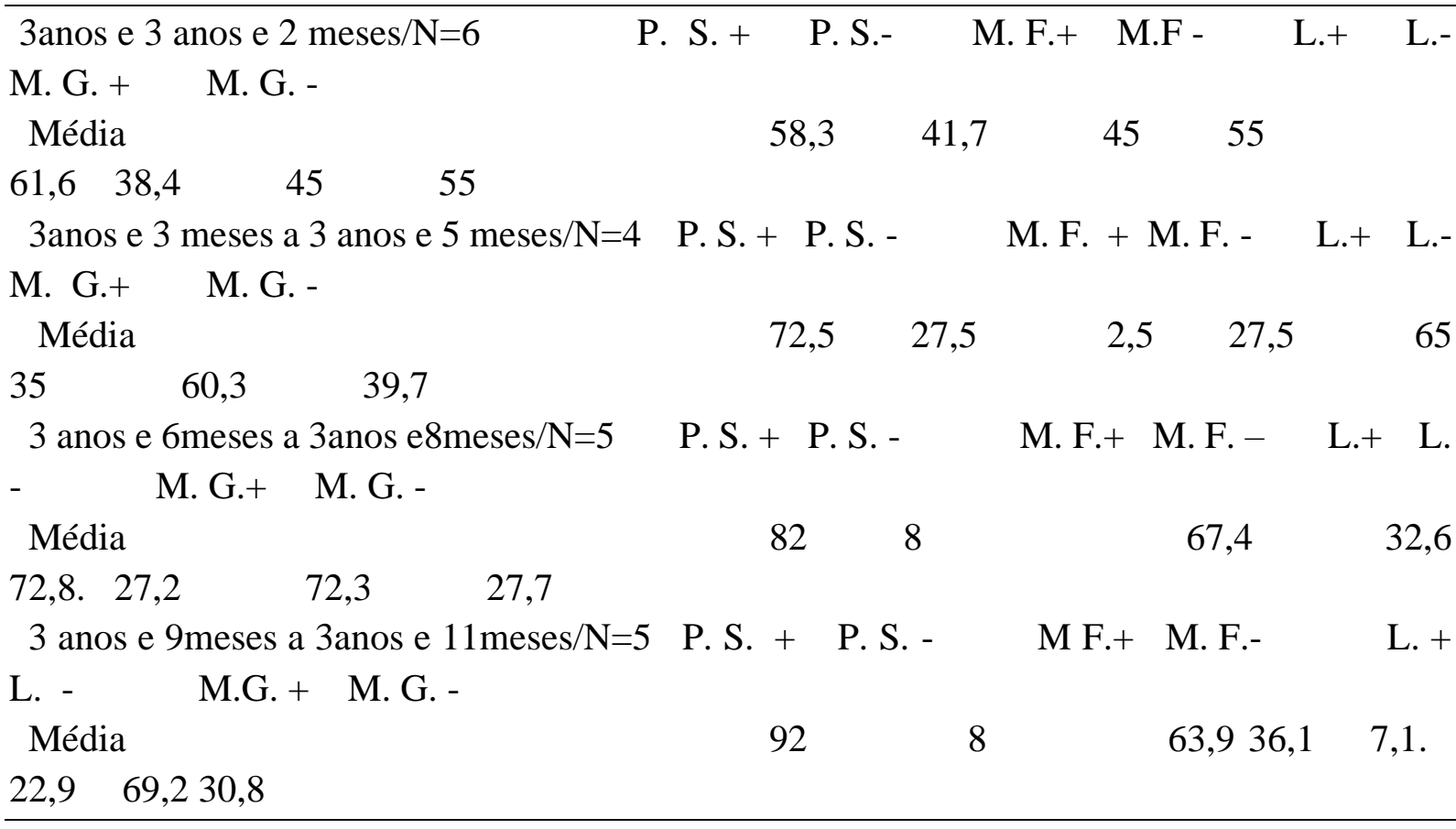

(+) Passou / (-) Falhou

Pessoal Social (P.S.); Motor Fino (M.F.); Linguagem (L.) e Motor Grosso (M.G)

$\mathrm{O}$ teste permitiu quantificar as crianças que mais apresentaram atraso no desenvolvimento neuropsicomotor foi $o$ grupo de 3 anos a 3,2 meses, onde pontuamos $45 \%$ de presença em ambos quesitos motor fino adaptativo e motor grosso (tabela 3). Para aprimorar o desenvolvimento das crianças foi sugerido aos professores para realizar as atividades semi-estruturadas que favorecessem no desempenho das habilidades motoras e linguagem de acordo com as falhas observadas na avaliação, tais como a coordenação visuo-motora, manuseio de blocos pequenos ao empilhar, pular, chutar bola, permanecer em um pé por alguns segundos, andar em linha reta, apresentaram também dificuldades nos conceitos de cor, quantidade, percepção corporal, preensão manual, linguagem receptiva (compreensão) e fala não inteligível.
Desta forma, para impulsionar a coordenação motora fỉna e ampla e a linguagem das crianças, foi sugerido as professoras, algumas atividades, cujo objetivo foi promover estímulos no desempenho de suas habilidades. Assim, as tarefas foram inseridas no calendário pedagógico no período de 2 (meses), sendo executado 3 (três) dias na semana, no turno da tarde, tendo em vista que as crianças se encontraram no período integral na unidade de ensino.

As atividades propostas aos educadores foram inseridas no calendário escolar durante o período da pesquisa, vale ressaltar que essas tarefas foram aplicadas a todos os alunos da creche, no entanto, os participantes da pesquisa ficaram em um grupo para melhor visualizar a desenvoltura da tarefa. Sugerido ainda, incluir no calendário pedagógico mais atividades lúdicas com o mesmo raciocínio, com isso 
reforçar o aprendizado, esta ideia foi bem aceita pela coordenação e professores.

Seguem as tarefas proposta pelos pesquisadores para favorecer a linguagem, a habilidade motora fina e grossa:

1. Pintura com cotonete (haste flexível de plástico com algodões em suas pontas) com uso de desenhos em folha de papel, completou as partes que faltavam da pintura com tinta $\mathrm{e}$ cotonete, onde trabalhou o conceito de cores primárias;

2. Colagem - realizou-se confecção de mini bolas de papel para colagem em partes do corpo, estimulou a aprendizado das cores associado ao desenho e a motricidade fina.

3. Contação de estórias - promoveu roda de contação de estórias lúdicas, assim, trabalhou a linguagem receptiva das crianças, contando-a por trechos e com pausas para pergunta-lhes: "quem, onde, para que?";

\section{Confecção de massa de modelar} caseira - materiais foram: farinha de trigo, óleo, sal, água, corante colorido, no qual estimulou conceito de cores e manuseio bimanual.

\section{Circuitos motores -}

materiais foram: pneus, bambolês, cones, cordas, e bolas coloridas (verde, vermelho, amarelo e azul), onde aprimorou a coordenação motora grossa, lateralidade, equilíbrio, noções espaciais e destreza.

Planejamento pedagógico seguiu desta forma:

- $\quad$ Em novembro a primeira semana de dezembro de 2017: no total de oito tardes, sendo estas subdivididas em duas vezes por semana, nestes meses executou as tarefas de contação de estórias, colagem e circuito motor.

- $\quad \mathrm{Na}$ última semana de janeiro a fevereiro de 2018, durante sete tardes, realizou-se atividades de circuito psicomotor, confecção de massa de modelar caseira, contação de estórias.

Devido a transferência de unidade de ensino, na reavaliação os grupos de 3 anos a 2 meses e 3 anos e 6 meses a 8 meses tiveram a perda de um aluno em cada. Já o de 3 anos e 3 meses a 5 meses apenas um aluno participou, não sendo contabilizado devido a diferenças estatística. (tabela 4). Após intervenção das pedagogas, foi reaplicada a Escala Denver II, a fim de verificar se houve ou não uma crescente nos itens avaliados pelo instrumento através do brincar. 
Tabela 4 -

Resultado da reavaliação da Escala Denver II de acordo com a faixa etária.

\begin{tabular}{|c|c|c|c|c|c|c|c|}
\hline $\begin{array}{l}\text { 3anos e } 3 \text { anos e } 2 \text { meses/N=5 } \\
\text { M. G.- }\end{array}$ & \multicolumn{2}{|c|}{ P.S. + P.S.- } & M. F.+ & M. F.- & \multicolumn{3}{|c|}{ L.+ L.- $\quad$ M. G.+ } \\
\hline Média & 70 & 30 & 54 & 56 & 66 & 34 & 60 \\
\hline 40 & & & & & & & \\
\hline $\begin{array}{l}3 \text { anos e } 6 \text { meses a } 3 \text { anos e } 8 \text { meses } / \mathrm{N}= \\
\text { G. }+ \text { M. G. - }\end{array}$ & $=4$. P.S. & + P.S. & M. F. + & M. F. - & L.t & L - & M. \\
\hline Média & 95 & 5 & 66 & 34 & 80 & 20 & 80 \\
\hline 20 & & & & & & & \\
\hline $\begin{array}{l}\text { 3anos e } 9 \text { meses a 3anos e } 11 \text { meses } / \mathrm{N}= \\
+\quad \text { M. G.- }\end{array}$ & $=5 \mathrm{P} . \mathrm{S}$. & P.S. & - M. F.+ & M. F.- & L. + L. & & M.G. \\
\hline Média & 96 & 4 & 66 & 34 & 80 & 20 & \\
\hline 16 & & & & & & & \\
\hline
\end{tabular}

(+) Passou / (-) Falhou

Pessoal Social (P.S.); Motor Fino (M.F.); Linguagem (L.) e Motor Grosso (M.G)

No grupo de 3, 3 meses e 3,5 meses participou apenas uma criança, e por este motivo não participou na contabilização.

Depois das orientações de tarefas semiestruturada e sua aplicabilidade, ocorreu um aumento significativo nas habilidades da coordenação motora fina de $54 \%$ e coordenação motora grossa de $60 \%$ (tabela 4).

Sobre a linguagem, mesmo com progressão ainda foram averiguadas dificuldades ao conceituar cores primárias (verde, amarelo, azul, vermelho), assim como na linguagem receptiva (algumas crianças não conseguiam compreender ao comando verbal), todavia, observou-se melhora na desenvoltura da fala (inteligível).

Vale ressaltar, que pontuando apenas o grupo correspondente a cada idade e baseando-se de acordo com as escalas (tabela 3 e 4), ocorreu aumento significativo no desempenho psicomotor, no entanto, vale frisar que o fator socioeconômico e escolaridade dos pais são fatores primordiais para se ter melhor aproveitamento escolar dos alunos em questão.

Logo, $55 \%$ dos pais são autônomos, com renda abaixo de um salário mínimo e 50 \% têm apenas o ensino fundamental incompleto (tabela 2). Sendo destes a metade só possuem a primeira série, é sugestivo que esses fatores podem ter interferido no desempenho das capacidades de suas crianças, cabendo apenas a escola realizar todo o papel de aprimorar as habilidades, que uma vez não tendo a parceria com os pais essas crianças tendem a ter um atraso no desenvolvimento neuropsicomotor.

\section{DISCUSSÃO}

O desempenho ocupacional da criança é baseado no interesse pelo brinquedo e de sua execução, onde está permite a criança a não se limitar apenas em seu campo visual, permitindo, portanto, que ela aja mesmo independente do que se vê 
fisicamente, mas evoluindo no seu campo imaginário. E sendo assim, o ambiente escolar, mas especificamente a sala de aula é um espaço para que as aptidões sejam desenvolvidas, usem a imaginação, criatividade e socialização com seus pares. (CONDESSA, 2018).

Diante disso, a sala de aula deve ser provida de recursos do brincar, sendo necessário que o recurso não fique apenas na escola, mas que seja usado como uma estratégia de ensino, que possibilitem a aprendizagem e o desenvolvimento integral da criança e que estimulem a interligação com os demais escolares. A sala de aula deve despertar o desejo nas crianças de descobrir o mundo ao seu redor, sendo que cada descoberta se agregue ao seu conhecimento progressivo.

Desta forma para Filho e Braga (2020), é fundamental que os escolares da educação infantil convivam em um meio onde possam manipular brinquedos, seja ele estruturado ou não, manusear objetos e inter-relacionar-se com outras, especialmente que tenham possibilidades de aprender, pois o brincar é um facilitador para comunicação verbal e não verbal, contribuindo, pois, para o processo de aprendizagem e o desenvolvimento integral da criança.

Verificou-se na escola, uma gama de recursos e brinquedos estruturados que estão à disposição das professoras. Foi presenciado que as educadoras criam em colaboração conjunta de seus alunos, brinquedos não estruturados, estimulando assim a criatividade e expressividade dos mesmos.

Os brinquedos não estruturados facilitam de maneira significativa o aprendizado, pois permitem a criança estruturar seu próprio brinquedo, necessitando assim de planejamento, de organização, de criação, manutenção da atenção, da concentração, memória operacional, sequencial e diversas outras capacidades cognitivas. Proporcionando resoluções de possíveis problemas que aparecerão em sua confecção e em seu uso na brincadeira.

Nesse sentido, brincando a criança recebe estímulos, que fornecem oportunidades da mesma explorar e experimentar situações que requerem tanto da motricidade ampla, quanto do uso do sistema sensorial, atuando assim como estimuladores para o desenvolvimento de áreas distintas, seja a motora, a cognitiva, a emocional ou a social (MAIA, et al. 2020).

Cabe ao professor, baseado no estudo de Souza e Teixeira (2020), estar atento ao brincar do estudante como um empoderamento da tarefa. E que o educador além de promover o ensino, deve também ser um mediador entre o brincar e a criança, para assim facilitar no desenvolvimento de suas capacidades. E enfatiza ainda que o ambiente seja favorável para estimular os alunos a ter interesse pelo espaço lúdico oferecido, onde a ludicidade é construída diante da ação executada pela criança com o brinquedo.

Teixeira e Volpini (2014), explica ainda que, para que aconteça o brincar na escola, é importante a presença do professor ou do auxiliar de sala. Se tornando essencial, pelo favorecimento e promoção da interação, por planejar e organizar ambientes para que o brincar possa acontecer, estimulando as ações cooperativas e a competitividade, o educador estimula na criança o desejo de brincar, auxiliando assim na aprendizagem. 
Condessa (2020) explica ainda que o ato de brincar é indispensável para o desenvolvimento integral infantil, pois por intermédio dele se aprende e começa a compreender acerca do ambiente em que está inserida, pela agregação de aspectos da realidade em seu mundo de faz de conta.

$\mathrm{Na}$ brincadeira, experienciam aspectos do dia-a-dia, relacionam-se com outras crianças e/ou adultos e consequentemente conquistam atitudes pautadas por regras e princípios morais e sociais. Desenvolvem a criatividade e a inteligência, adquire autoconhecimento e conquista a sua autonomia, além da capacidade de resolução de problemas.

Destarte, a educação infantil pautada no alicerce lúdico e com apoio familiar é de suma importância para que a criança obtenha ganhos em seu desenvolvimento neuropsicomotor.

\section{CONCLUSÃO}

Esse estudo investigou, a influência do brincar na aquisição dos componentes de desempenho das crianças no contexto escolar. Para coleta da pesquisa, utilizou-se o teste de triagem do desenvolvimento, Denver II, que teve por finalidade comparar as crianças que apresentaram atraso em suas habilidades com outras correspondentes a mesma idade, observou-se em algumas áreas, que as crianças apresentaram dificuldades em realizar tarefas. Diante disso, foi pontuado alguns quesitos que mais apresentaram atraso no desempenho psicomotor e na linguagem, entretanto, no geral, mesmo as crianças com estimulo educacional pautado no lúdico, ainda apresentaram dificuldades de entender e executá-las e para minimizar tais déficits. Foi orientado as educadoras a aplicarem atividades lúdicas que estivesse pautada na criatividade, na destreza bimanual e habilidade no equilíbrio.

Verificou-se que, com a colaboração e empenho das professoras durante sua aplicação, houve um crescente ganho na compreensão dos alunos acerca do que estava sendo direcionado e perguntado, devido à coerência na prática das brincadeiras.

Foi observado também que a práxis das tarefas contribuiu para o aprendizado das habilidades motricidade fina e grossa, cognitivas e a sua formação social. Bem como na desenvoltura da fala nãointeligível.

É sugestivo ainda, que as crianças em seu ambiente escolar tenham ainda tarefas recreativas que possam estimular a buscarem interessem em aprender, onde a ludicidade é construída diante da ação executada pela criança com o brinquedo. Sendo este, portanto, o auxiliador em seu desenvolvimento neuropsicomotor correspondente a sua idade.

Considerando a temática ser de suma importância para o desenvolvimento infantil, ainda são poucas as pesquisas realizadas deste tipo de conteúdo no Brasil, fazendo-se necessário a realização de novos estudos acerca dessa abordagem para nortear o cuidador e o professor no processo da aprendizagem da criança, onde a mesma aprende em função das interações consigo, com outro e o contexto que está inserida, das experiências trocadas com os colegas, da observação e do ensinamento, ou seja, essas interações são uma engrenagem para a formação da capacidade no desempenho ocupacional dos alunos e deve ser incentivadas em políticas públicas do sistema educacional. 


\section{REFERÊNCIAS}

CAMPOS, S. D. F.; FIGUEIREDO, M O et al. $O$ brincar para o desenvolvimento do esquema corporal, orientação espacial e temporal: análise de uma intervenção. Cadernos Brasileiros de Terapia Ocupacional, São Carlos, v. 25, n. 2, p. 275-285, 2017.

BURCKARDT, E. V.; COSTA, L. C. C.; KUNZ, E. As relações do brinquedo industrializado com o brincar e semovimentar: uma reflexão na Educação Física. Motrivivência, Florianópolis/SC, v. 30, n. 54, p. 278-294, julho/2018.

ADREETA, T. E.; GOING, L. C.; SAKAMOTO, C. K. brincar e a escola: um estudo sobre o lúdico no primeiro ano do ensino fundamental. Bol. - Acad. Paul. Psicol. vol.40 no.98 São Paulo jan./jun. 2020

PORTA, D. S. C.; SANTANA, M. L. S et al. Neuropsicoeducação e Inclusão

Escolar: Interlocuções Iniciais.II Congresso Internacional de Educação Inclusiva, 2016. Disponível em: $<$ http://editorarealize.com,br/revistas/cinte di/trabalhos $>$. Acesso em: 18 de junho de 2021.

TOLOCKA, R.E.; et al. Vamos brincar na "escolinha"? inserindo atividades de jogos e brincadeiras em escolas de ensino infantil. Licere, Belo Horizonte, v.19, n.1, mar/2016.

MELO, T. L.; MENEZES, A. O.; SANTOS, E. J.; SILVA, L. B.; FREITAS, R.B. NEUROPLASTICIDADE. Revista de Trabalhos Acadêmicos - Universo Recife, VOL. 4, NO 2 (2017).
FREITAS, C. N.; CORSO, H. V.; A psicopedagogia na educação infantil: o papel das brincadeiras na prevenção das dificuldades de aprendizagem. Ver. Psicopedag. Vol. 33 no. 101, São Paulo, 2016.

FRANKENBURG, W.K. et al. The Denver II: a major revision and restandardization of the Denver developmental screening test. Pediatrics 1992; 89:91-7

MORAES, M.W., et al.Teste de Denver II: avaliação do desenvolvimento de crianças atendidas no ambulatório do Projeto Einstein na Comunidade de Paraisópolis. Einstein, v.8, n.2, p.149-153, 2010.

BRETAS, J.R.S.; et al. A aplicação do teste de triagem do desenvolvimento de Denver pelo enfermeiro pediatra: relato de caso. Acta Paul. Enferm, v.8, n.4, p.918, 1995.

CONDESSA, I. C. A cultura lúdica infantil na escola atual: Estão as crianças a ser deixadas para trás? Revista Zero - a - seis. ISS Ne 1980-4512, v. 20 , n. 38 , p. $272-287$, julho-dezembro 2018 .

FILHO, H. V. A.; BRAGA, L. M. As atividades lúdicas como ferramentas de aprendizagem na educação infantil: um panorama das pesquisas. Pensar Acadêmico, Manhuaçu, v. 18, n.2, p. 339358, maio-agosto, 2020.

MAIA, D. F.; FARIAS, A. L. P.; OLIVEIRA, M. A. T. Jogos e brincadeiras nas aulas de educação 